Article

\title{
An Exploratory Analysis of Factors Associated with Health-Related Physical Fitness in Adolescents. The ASSO Project
}

\author{
Antonino Bianco ${ }^{1, *(1)}$, Ambra Gentile ${ }^{2}$ (D), Stefano Boca ${ }^{1}$, Antonio Paoli ${ }^{3}(\mathbb{D})$ \\ Giuseppe Messina ${ }^{4}$, Manuel Gómez-López ${ }^{5}$ (D), Antonio Palma ${ }^{1}$ and Garden Tabacchi ${ }^{1}$ \\ 1 Sport and Exercise Sciences Research Unit, SPPF Department, University of Palermo, 90144 Palermo, Italy; \\ stefano.boca@unipa.it (S.B.); antonio.palma@unipa.it (A.P.); tabacchi.garden@libero.it (G.T.) \\ 2 PhD Program in Health Promotion and Cognitive Sciences, University of Palermo, 90128 Palermo, Italy; \\ ambra.gentile91@gmail.com \\ 3 Department of Biomedical Sciences, University of Padua, 35100 Padua, Italy; antonio.paoli@unipd.it \\ 4 POSTURALAB Italia, 90100 Palermo, Italy; posturalab@icloud.com \\ 5 Department of Physical Activity and Sport, University of Murcia, 30720 Murcia, Spain; mgomezlop@um.es \\ * Correspondence: antonino.bianco@unipa.it; Tel.: +39-091-2389-6910; Fax: +39-091-2386-0894
}

Received: 29 March 2018; Accepted: 29 May 2018; Published: 2 June 2018

check for updates

\begin{abstract}
Monitoring physical fitness (fitness) and identifying, since the beginning, possible determinants in youth could be useful to preserve health and avoid morbidities in adulthood. The main objective of this study is to provide details on the fitness levels of a sample of adolescents living in the Southern area of Italy and describe its associations with biological/genetic, socio-cultural/environmental, and lifestyle (physical activity/sedentariness, alcohol/smoking, meal patterns/habits) factors. The study was conducted within the Adolescence Surveillance System for Obesity Prevention (ASSO) project, funded by the Italian Ministry of Health and examining adolescents' lifestyle in relation to obesity. Fitness measures were collected through the ASSO-fitness tests battery (FTB) and examined in relation to 79 selected possible influencing factors, which were collected through a web-based questionnaire included in the ASSO-NutFit software. Logistic regression analyses were performed to assess associations, with ORs and 95\% CIs estimated as crude and adjusted. A total of 919 participants were initially recruited, but fitness data were collected for 544 students aged $13-19(68 \%$ M, 32\% F). Fitness level was low for $14.2 \%$ of the students, medium for $67.8 \%$, and high for $18.0 \%$. The independent determinants of low physical fitness in our sample of adolescents were included in the biological/genetic and physical activity/sedentariness dimensions: female gender (Adj OR 8.33, CI 2.08-33.33), obesity (Adj OR 1.97, CI 1.10-9.22), practicing sport less than $3 \mathrm{~h}$ /week (Adj OR 6.09, CI 1.63-22.72), practicing sport with strength/speed as prevalent biomotor ability (Adj OR 8.97, CI 1.43-56.19), using PC/internet for more than $3 \mathrm{~h} /$ day (Adj OR 4.46, CI 1.17-16.98). Drinking alcohol was instead a protective factor. This study confirms that females and obese individuals need more attention in the interventions aimed at increasing fitness levels. It suggests that local actions should be implemented with the aim of increasing sport practices and reducing sedentary time spent in front of PC/internet. The focus should be particularly addressed to sports with strength or speed as dominant biomotor abilities.
\end{abstract}

Keywords: physical fitness; ASSO project; health promotion; lifestyle

\section{Introduction}

The relationship between health-related physical fitness (fitness) and health status of young people has been previously demonstrated [1-5]. It is also clear that fitness levels should be monitored 
in order to preserve health and prevent morbidities in adulthood for several disorders, including cardiovascular diseases, obesity, metabolic syndrome, and also mortality, and to reduce health care costs [6-9]. Moreover, fitness is related to academic performance that includes cognitive skills and attitudes (e.g., attention, memory, comprehension), academic behaviors (e.g., organization, attendance, impulse control), and achievement (e.g., standardized test scores, grade point averages) [10-13]. As mentioned above, scientific literature reports the relation among low fitness levels of adolescents and several factors involving genetic, biological, familiar, environmental, and behavioral aspects, such as female gender, low income, low consumption of dairy products and/or bread/cereals, increased consumption of sweetened beverages, insufficient physical activity level, excessive screen time, and excess body fat [14-17]. School represents the correct environment where adolescents' fitness could be assessed and monitored [12,18], with the aim of identifying possible low fitness levels and use appropriate interventions to increase them. Moreover, the identification of the factors that could influence fitness levels since childhood or adolescence is important and should be carried out in parallel with fitness monitoring [14].

Even though risk factor analysis nowadays represents a new challenge in many research fields, included also health promotion, sociodemographic, and behavioral sciences $[1,19]$, as far as we know only few studies used it to report data concerning the potential association between physical fitness and risk factors [20,21]. Information on adolescents' physical fitness in different geographical areas and according to different cultures is very important to drive public health actions aimed at preventing the above-mentioned disorders in the adult life. To our knowledge, no data on the determinants of fitness level are available in the literature on adolescents from Southern Italy. In this context falls the Adolescents and Surveillance System for Obesity prevention project (ASSO), which was funded by the Italian Ministry of Health. The project developed different tools for the collection of adolescents' health assessments and proposed a surveillance system eligible at national level $[18,22-26]$. Detailed information on adolescents' fitness and several possible related variables were also collected within the project. The main purpose of this investigation is to provide a framework of the fitness level of adolescents living in the Southern area of Italy and describe its association with different biological/genetic, socio-cultural/environmental, and lifestyle factors, in order to supply stakeholders with substantial information useful to target prevention policies and action plans in the public health sector.

\section{Materials and Methods}

The ASSO study protocol was approved by the Ethical Committee of the Azienda Ospedaliera Universitaria Policlinico "Paolo Giaccone" in Palermo (approval code no. 9/2011). All procedures were accurately prepared and multidisciplinary ASSO team members-including researchers, school teachers, and experts-were trained and provided with proper standard operating procedures (SOPs). These procedures described in detail the use of the ASSO tools that included an ASSO-fitness test battery (FTB) $[18,24]$ to assess students' health-related fitness, a set of classic anthropometric tools and a web-based software ASSO-NutFit [22] to collect data on biological/genetic factors, socio-cultural and environmental variables, and life habits.

\subsection{ASSO-FTB and Anthropometric Tools}

The ASSO-FTB is made up of five selected tests for the assessment of the physical fitness components: (1) the hand-grip strength test (HGt) to assess upper body maximal strength; (2) the standing broad jump test (SBJt) to assess lower body maximal strength; (3) the sit ups test to exhaustion (SUtex) to assess muscular endurance; (4) the $4 \times 10 \mathrm{~m}$ shuttle run test $(4 \times 10 \mathrm{~m} \mathrm{SRt})$ to assess speed and agility; and (5) the $20 \mathrm{~m}$ shuttle run test ( $20 \mathrm{~m} \mathrm{SRt}$ ) to assess endurance/aerobic capacity [24]. The best score of three performances was retained for the subsequent analysis, except for the SUtex and the $20 \mathrm{~m} \mathrm{SRt}$, which were performed only once. From the measures of the five major physical fitness components, through the principal components analysis (PCA), a continuous fitness level score (the 
Fit-Score), and a Likert-type scale on the Fit-Score values was applied to obtain a classification of the individual level of fitness: very poor $(\mathrm{X}<\mathrm{P} 20)$, poor (P20 $\leq \mathrm{X}<\mathrm{P} 40)$, medium (P40 $\leq \mathrm{X}<\mathrm{P} 60)$, good (P60 $\leq X<P 80)$, and very good ( $X \geq P 80)$ [24]. Teachers of motor activity were responsible both of fitness and anthropometric (weight, height, and waist circumference) measurements. These last ones were collected using a calibrated scale, a stadiometer and a non-elastic meter, respectively, provided by the schools. Weight status categories were taken from the cut off points by the International Obesity Task Force $[27,28]$.

\subsection{ASSO-NutFit Software}

The web-based ASSO-NutFit software included all questionnaires to collect different variables, i.e., the ASSO-PIQ (personal information questionnaire), with questions regarding participant and family information, neonatal and clinical assessment; the ASSO-PASAQ (physical activity, smoke, and alcohol questionnaire), for physical activity, smoking, alcoholic drinks and other beverages assessment; and the ASSO-FHQ (food habits questionnaire), which consisted of six items regarding breakfast, school break, lunch, afternoon break, dinner, and various habits such as eating out, eating ready meals, organic food, fresh food, or food from vending machines. The last questionnaire is the ASSO-FFQ (food frequency questionnaire), that was not used for the purpose of this study [22]. The principles of the Italian data protection $(196 / 2003)$ were guaranteed for the collected information. A multi-phase sampling was used to recruit students from classes first to fourth of public and private high schools in Palermo city, in the year 2013. Participants were asked to provide informed consent signed by their parents.

\subsection{Variables}

The five classes of fitness level determined through the PCA were categorized into three classes $(0=$ high, $1=$ medium, and $2=$ low $)$, and subsequently for the purpose of the logistic regression analysis into two classes $(0=$ high $/$ medium and $1=$ low $)$. Risk factors examined for the associations were recorded in dichotomized classes with ' 0 ' representing a healthier factor and ' 1 ' representing a less healthy factor.

Possible determinants of fitness level addressed in the survey included initially 79 items, which were gathered into three dimensions, including (1) biological/genetic; (2) socio-cultural and environmental; and (3) lifestyle (physical activity/sedentariness, alcohol/smoking, meal patterns/ habits). These dimensions were chosen by the authors according to recent literature that used ecological models to classify and conceptualize determinants of sedentary behavior, such as the social-ecological framework for the determinants of sedentary behaviors $[19,29,30]$ and they were adapted for the purpose of this study to the fitness and to the available project's data collected.

Among the biological and genetic factors, the following were considered for the associations: gender, age, weight status, birth weight, delivery time, delivery type, breastfeeding, breastfeeding duration, weaning time, metabolic risk, alcoholic risk, health risk, diagnosed diseases, parental diseases, malaise frequency, and overweight/obese parents. Age was categorized into students $<16$ and $\geq 16$ years. Weight status was assessed according to the international BMI cut-off points developed by the Centers for Disease Control and Prevention (CDC) [31]. Birth weight was considered normal if comprised between 2.5 and $3.5 \mathrm{Kg}$; delivery time was categorized into full-term and pre-term, with pre-term birth being before 37 weeks of gestation; delivery time was natural or caesarean; breastfeeding (yes, not), breastfeeding duration ( $3-5$ months, 6 months) and weaning ( $3-5$ months, 6 months). The waist-to-height ratio was used to estimate the metabolic risk [32,33], while alcoholic risk was calculated on the basis of ethanol daily intake higher than $12 \mathrm{~g}$. These risks are both indices of health risk, so they were assembled into one variable named "health risk", with all adolescents showing both these parameters included in this class. The presence of diseases in adolescents was reported as diagnosed by a medical doctor. The malaise frequency was the frequency of the presence of subjective health complaints (SHCs) measured through an eight items checklist ("headache", "stomach 
ache", "backache", "feeling low", "irritable or bad tempered", "feeling nervous or anxious", "sleeping difficulties", and "dizziness") previously developed in the HBSC study (health behavior in school-aged children) [34], and adopted as such in the ASSO toolkit. Adolescents reported in the questionnaire also their parents' weight status, with those having at least one parent overweight or obese considered at genetic risk.

Socio-cultural and environmental factors included: nationality; town of residence size (big, small center); study course type (lyceum, professional/technical institute), school type (public, private), school class, shared bedroom, number of family members, number of siblings, parents' nationality, parents' education (high including high school and university, and low including lower education classes), parents' occupation, parents' civil status (married, non-married), and family affluence scale (FAS), constructed by the sum of scores of the answers to questions about the presence of common goods such as computers, number of cars, single bedroom, and annual holidays [35].

Life habits included physical activity/sedentariness, alcohol consumption, smoking, and meal patterns/habits.

Different physical activities were summed up, such as playing outside, walking, going to school by active transportation means, doing motor activity at school, practicing sport, as well as sedentary activities, such as sleeping hours, doing homework, reading, watching TV, videogame playing, using $\mathrm{PC} /$ internet. Sedentary individuals were those showing a total screen time equal to or higher than $3 \mathrm{~h} /$ day (American Academy of Pediatrics 2001). Practicing sport (intended as vigorous intensity activity) for at least three hours/week was another indicator of high physical activity level [36].

Smoking habits included the variables of smoking at least once in life, current smoking and numbers of cigarettes per day. Among the alcohol habits, drinking alcohol, type of alcohol preference, and alcohol intake in days/week were the variables selected for the analysis.

The meal/food habits comprised different variables. An "adequate" breakfast or morning and afternoon breaks excluded carbonated beverages or other junk food; and an "adequate" lunch or dinner included a first or a second course with vegetables, fruit, bread, and excluded carbonated beverages or other junk food. Meals were considerate adequate in general if subjects consumed at least three adequate meals per day.

Eating out, eating industrial foods, eating organic food, eating fresh food and eating food from vending machines (never/rarely, weekly/daily) were summarized into one variable named "food habits" ('correct' if subjects had at least four correct behaviors).

Other habits were the use and type of supplements, having been advised a diet by the doctor, following a slimming regime.

All considered variables are included in Table 1. 
Table 1. Descriptive statistics of the population sample. Asterisks on the variables indicate positive association with high fitness level (assessed through chi-square test).

\begin{tabular}{|c|c|c|c|c|c|c|c|c|c|c|c|}
\hline \multicolumn{12}{|c|}{ BIOLOGICAL/GENETIC FACTORS } \\
\hline & $\mathrm{n}$ & $\%$ & & $\mathbf{n}$ & $\%$ & & $\mathbf{n}$ & $\%$ & & $\mathbf{n}$ & $\%$ \\
\hline Gender & & & Age & & & Weight status & & & Birth weight & & \\
\hline Male *** & 571 & 62.1 & $<16$ years & 348 & 38.1 & Normal/under* & 583 & 71.9 & Normal & 490 & 65.6 \\
\hline Female & 348 & 37.9 & $\geq 16$ years & 566 & 61.9 & Overweight/obese & 228 & 28.1 & Under/Overweight & 257 & 34.4 \\
\hline Delivery time & & & Delivery type & & & Breastfeeding & & & Breastfeeding duration & & \\
\hline Full-term * & 622 & 83.3 & Natural & 402 & 53.8 & Yes & 598 & 80.0 & $<5$ months & 217 & 36.3 \\
\hline Pre-term & 125 & 16.7 & Caesarean & 345 & 46.2 & Not & 149 & 20.0 & $\geq 5$ months & 381 & 63.7 \\
\hline Weaning time & & & Metabolic risk & & & Alcoholic risk & & & Diagnosed diseases & & \\
\hline $3-5$ months & 563 & 75.4 & $\mathrm{No}^{* * *}$ & 533 & 72.7 & No & 686 & 88.9 & No & 651 & 87.1 \\
\hline 6 months & 184 & 24.6 & Yes & 200 & 27.3 & Yes* & 86 & 11.1 & Yes & 96 & 12.9 \\
\hline Malaise frequency & & & Health risk ${ }^{a}$ & & & Parents/family diseases & & & Overweight/obese parents & & \\
\hline Never/rarely ** & 589 & 83.1 & No & 629 & 73.7 & $\mathrm{No}^{*}$ & 298 & 39.9 & None & 227 & 31.0 \\
\hline Weekly/daily & 120 & 16.9 & Yes & 225 & 26.3 & Yes & 449 & 60.1 & At least one & 506 & 69.0 \\
\hline Father's weight status & & & Mother's weight status & & & & & & & & \\
\hline Normal/under & 292 & 39.8 & Normal/under & 500 & 67.6 & & & & & & \\
\hline Overweight/obese & 441 & 60.1 & Overweight/obese & 240 & 32.4 & & & & & & \\
\hline \multicolumn{12}{|c|}{ SOCIO-CULTURAL AND ENVIRONMENTAL FACTORS } \\
\hline School type & & & School class & & & Study course type & & & Family Affluence Scale & & \\
\hline Public & 752 & 81.8 & 1 st- 2 nd class & 379 & 41.2 & Lyceum & 411 & 44.7 & High & 409 & 54.8 \\
\hline Private * & 167 & 18.2 & 3rd-4th class * & 540 & 58.8 & Professional/technical & 508 & 55.3 & Medium/low & 338 & 45.2 \\
\hline No. family members & & & No. siblings & & & Father's nationality & & & Mother's nationality & & \\
\hline 4 or more & 614 & 82.2 & 1 or more & 609 & 81.4 & Italian & 714 & 97.1 & Italian & 714 & 96.2 \\
\hline $1-3$ & 133 & 17.8 & none & 139 & 18.6 & Other & 21 & 2.9 & Other & 28 & 3.8 \\
\hline Father's education & & & Mother's education & & & Father's occupation & & & Father's occupation type & & \\
\hline High & 502 & 68.3 & High & 516 & 69.5 & Occupied & 684 & 93.1 & Non manual job & 416 & 64.2 \\
\hline Low & 233 & 31.7 & Low & 226 & 30.5 & Other ${ }^{c}$ & 51 & 6.9 & Manual job & 232 & 35.8 \\
\hline Father's occupation extent & & & Mother's occupation & & & Mother's occupation type & & & Mother's occupation extent & & \\
\hline Full-time* & 371 & 89.2 & Occupied & 433 & 58.4 & Non manual job & 324 & 77.3 & Full-time & 263 & 81.2 \\
\hline Part-time & 45 & 10.8 & Other $\mathrm{b}$ & 309 & 41.6 & Manual job & 95 & 22.7 & Part-time & 61 & 18.8 \\
\hline
\end{tabular}


Table 1. Cont.

\begin{tabular}{|c|c|c|c|c|c|c|c|c|c|c|c|}
\hline \multicolumn{12}{|c|}{ LIFE HABITS } \\
\hline \multicolumn{12}{|c|}{ Physical activity/Sedentariness } \\
\hline Physical activity & & & Playing outside (h/day) & & & Walking (h/day) & & & Way to go to school & & \\
\hline More than $60 \mathrm{~min} /$ day * & 726 & 93.4 & 1 or more & 142 & 40.7 & 1 or more & 260 & 43.2 & walking/biking & 190 & 24.6 \\
\hline Less than $60 \mathrm{~min} /$ day & 51 & 6.6 & Less than 1 & 207 & 59.3 & Less than 1 & 342 & 56.8 & $\mathrm{car} / \mathrm{bus} / \mathrm{metro} / \mathrm{tram} /$ train & 582 & 75.4 \\
\hline Practicing sport & & & No. sports practiced & & & Sport (h/week) & & & Sport type & & \\
\hline Yes* & 609 & 78.9 & More than 1 & 266 & 43.8 & 3 or more *** & 477 & 61.8 & Team* & 388 & 63.9 \\
\hline No & 163 & 21.1 & 1 & 341 & 56.2 & Less than 3 & 295 & 38.2 & Individual & 219 & 36.1 \\
\hline Sport biomotor ability & & & Sleeping (h/day) & & & Doing homeworks & & & Reading (h/day) & & \\
\hline Endurance * & 504 & 83.0 & Less than 7 & 126 & 16.3 & 1 or less & 371 & 80.5 & 1 or less & 249 & 67.5 \\
\hline Strength/Speed & 103 & 17.0 & 7 or more & 646 & 83.7 & More than 1 & 100 & 19.5 & More than 1 & 120 & 32.5 \\
\hline Total screen time (h/day) & & & TV watching (h/day) & & & Videogames playing (h/day) & & & Using PC/internet (h/day) & & \\
\hline Less than 3 & 448 & 57.1 & 2 or less & 430 & 67.4 & 1 or less & 311 & 65.1 & 1 or less* & 359 & 51.4 \\
\hline 3 or more & 336 & 42.9 & More than 2 & 208 & 32.6 & More than 1 & 167 & 34.9 & More than 1 & 340 & 48.6 \\
\hline \multicolumn{12}{|c|}{ Smoking } \\
\hline Smoking at least once in life & & & Current smoking & & & Cigarettes no./day & & & & & \\
\hline No & 474 & 61.4 & No & 665 & 86.1 & Less than 5 & 34 & 31.8 & & & \\
\hline Yes & 298 & 38.6 & Yes & 107 & 13.9 & Five or more & 72 & 68.2 & & & \\
\hline \multicolumn{12}{|c|}{ Alcohol consumption } \\
\hline Drinking alcohol & & & Alcohol preference & & & Alcohol days/week & & & Food habits in general ${ }^{\mathrm{d}}$ & & \\
\hline No & 276 & 35.8 & Slightly alcoholic drinks, beer, wine & 290 & 58.5 & Less than 1 & 703 & 91.1 & Correct & 388 & 50.3 \\
\hline Yes *** & 496 & 64.2 & Cocktails, liqueurs & 206 & 41.5 & One or more & 69 & 8.9 & Incorrect & 384 & 49.7 \\
\hline
\end{tabular}

${ }^{*} p<0.05 ;{ }^{* *} p<0.01 ;{ }^{* * *} p<0.001{ }^{a}{ }^{a}$ Adolescents at health risk are those who are both at metabolic and alcoholic risk; ${ }^{\mathrm{b}}$ Other $=$ non-occupied, retired, housewife, student. ${ }^{\mathrm{c}}$ A proper meal

excluded carbonated beverages or other junk food, for the breakfast or morning and afternoon breaks; and a proper meal including a first or a second course with vegetables, fruit, bread,

and excluding carbonated beverages or other junk food, for lunch and dinner. ${ }^{\mathrm{d}}$ Food habits were derived by summing up eating out, eating ready meals, eating organic food, eating fresh

food, eating food from vending machines. They were considered 'correct' if subjects had at least four correct behaviors. 


\subsection{Statistical Analysis}

The chi-squared test was applied to assess correlations between fitness level and all the considered variables. Factors that resulted associated were included in a logistic regression model and used to derive odds ratios (OR) and $95 \%$ confidence intervals (CI), and the adjusted ORs and CIs after controlling for potential confounders. Statistical significance was set at $p<0.05$. The Stata/MP 12.0 software was used for the analyses (StataCorpLP, college Station, TX, USA).

\section{Results}

A total of 919 participants were initially recruited. Fitness tests comprising all the five tests included in the battery were collected for 544 students aged $13-19$ (68\% males, 32\% females; mean age $16.3 \pm 1.4$ years) within the ASSO project [22,24]. Fitness level was low for $14.2 \%$ of the students, medium for $67.8 \%$, and high for $18.0 \%$.

In Table 1, descriptive data show the frequencies of the different considered factors and their correlation with fitness levels. The following 17 variables were found associated with fitness levels: gender, weight status, metabolic risk, alcoholic risk, malaise frequency, parents / family diseases (among the biological/genetic factors); school class, school public or private, father's occupation extent (among the socio-cultural and environmental factors); minutes/day of physical activity, practicing sport, hours/week of sport, sport type (team or individual), biomotor ability prevalent in the practiced sport (endurance or strength/speed), using PC/internet, drinking alcohol, doctor advised diet (among the life habits).

After multivariate logistic regression analysis, the independent factors associated with fitness levels were the following: gender, weight status, practicing sport, hours/week of sport, prevalent sport biomotor ability, using PC/internet, drinking alcohol (Table 2). Female gender increased the risk of poor fitness level of eight times (Adj OR 8.33, CI 2.08-33.33); for the weight status, the risk of poor fitness level was around twice higher for obese (OR 1.97, CI 1.10-9.22) compared to normal weight children. Practicing less than $3 \mathrm{~h} /$ week of sport and practicing a sport of strength/speed increased the risk of poor fitness level of around six and nine times, respectively (Adj OR 6.09, CI 1.63-22.72; Adj OR 8.97, CI 1.43-56.19) compared to practicing more than $3 \mathrm{~h} /$ week and practicing a sport of endurance. The likelihood of having low fitness level was four and a half times higher for adolescents spending more than $1 \mathrm{~h} /$ day in front of PC/internet (Adj OR 4.46, CI 1.17-16.98). Unexpectedly, those drinking alcohol were more likely to have high fitness levels (OR 0.21, CI 0.06-0.77).

Table 2. Raw and adjusted odds ratio (OR) with 95\% confidence interval (CI) performed through logistic regression of the subjects' fitness level.

\begin{tabular}{ccc}
\hline & Low Fitness Level (Medium/High as Reference) \\
\hline Variables & OR $(95 \%$ CI $)$ & Adj OR $(95 \%$ CI $)$ \\
Gender & 1.00 & 1.00 \\
Female & $0.17(0.1-0.3)^{* * *}$ & $0.12(0.03-0.48)^{* *}$ \\
Male & 1.00 & 1.00 \\
Weight status & $2.22(0.90-5.48)$ & $3.43(0.02-8.67)$ \\
Normal weight & $1.31(0.71-22.39)$ & $2.98(0.01-6.75)$ \\
Underweight & $2.74(1.19-6.26)^{*}$ & $1.97(1.10-9.22)^{*}$ \\
Overweight & & \\
Obese & 1.00 & 1.00 \\
Metabolic risk & $1.99(1.16-3.36)^{* * *}$ & $2.35(0.38-14.62)$ \\
No & 1.00 & 1.00 \\
Yes & $0.16(0.00-0.97) *$ & $0.81(0.04-15.00)$ \\
Alcoholic risk & & \\
No & & \\
Yes & &
\end{tabular}


Table 2. Cont.

\begin{tabular}{|c|c|c|}
\hline \multirow[b]{2}{*}{ Variables } & \multicolumn{2}{|c|}{ Low Fitness Level (Medium/High as Reference) } \\
\hline & OR $(95 \% C I)$ & $\operatorname{Adj}$ OR $(95 \% \mathrm{CI})$ \\
\hline \multicolumn{3}{|l|}{ Malaise frequency } \\
\hline Never/rarely & 1.00 & 1.00 \\
\hline Weekly/daily & $2.41(1.16-4.82) * *$ & $1.05(0.26-4.22)$ \\
\hline \multicolumn{3}{|c|}{ Parents/family diseases } \\
\hline No & 1.00 & 1.00 \\
\hline Yes & $2.01(1.07-3.93) *$ & $2.36(0.61-9.06)$ \\
\hline \multicolumn{3}{|l|}{ School class } \\
\hline 1st-2nd classes & 1.00 & 1.00 \\
\hline 3rd-4th classes & $0.53(0.32-0.90) *$ & $1.04(0.25-4.35)$ \\
\hline \multicolumn{3}{|l|}{ School } \\
\hline Private & 1.00 & 1.00 \\
\hline Public & $2.13(1.11-4.35) *$ & $2.23(0.25-4.35)$ \\
\hline \multicolumn{3}{|c|}{ Father's occupation extent } \\
\hline Full-time & 1.00 & 1.00 \\
\hline Part-time & $3.04(0.97-8.55) *$ & $4.86(0.91-25.94)$ \\
\hline \multicolumn{3}{|l|}{ Physical activity } \\
\hline$\geq 60 \mathrm{~min} /$ day & 1.00 & 1.00 \\
\hline$<60 \mathrm{~min} /$ day & $2.22(0.01-5.27) *$ & $0.32(0.01-12.62)$ \\
\hline \multicolumn{3}{|l|}{ Practicing sport } \\
\hline Yes & 1.00 & 1.00 \\
\hline No & $2.01(1.02-3.81)^{*}$ & 1.00 \\
\hline \multicolumn{3}{|l|}{ Hours/week of sport } \\
\hline$\geq 3 \mathrm{~h}$ & 1.00 & 1.00 \\
\hline$<3 \mathrm{~h}$ & $3.17(1.81-5.56)^{* * *}$ & $6.09(1.63-22.72) * *$ \\
\hline \multicolumn{3}{|l|}{ Sport type } \\
\hline Team & 1.00 & 1.00 \\
\hline Individual & $2.09(1.10-3.96) *$ & $0.79(0.15-4.19)$ \\
\hline \multicolumn{3}{|c|}{ Sport dominant biomotor ability } \\
\hline Endurance & 1.00 & 1.00 \\
\hline Strength/speed & $2.19(1.04-4.41) *$ & $8.97(1.43-56.19) *$ \\
\hline \multicolumn{3}{|l|}{ PC/internet time } \\
\hline$\leq 1 \mathrm{~h}$ & 1.00 & 1.00 \\
\hline$>1 \mathrm{~h}$ & $1.92(1.08-3.48) *$ & $4.46(1.17-16.98)$ * \\
\hline \multicolumn{3}{|c|}{ Drinking alcoholic beverages } \\
\hline No & 1.00 & 1.00 \\
\hline Yes & $0.26(0.14-0.46)^{* * *}$ & $0.21(0.06-0.77) *$ \\
\hline \multicolumn{3}{|l|}{ Doctor advised diet } \\
\hline No & 1.00 & 1.00 \\
\hline Yes & $3.29(1.47-7.00) * * *$ & $4.49(0.45-45.22)$ \\
\hline
\end{tabular}

\section{Discussion}

In this study, fitness levels and fitness-related factors were taken into account on a sample of adolescents attending high schools from Southern Italy. Results show that the main predictors of low physical fitness in our sample of adolescents are included in the biological/genetic and lifestyle (physical activity/sedentariness) dimensions.

With regard to the biological/genetic dimension, gender differences were found in the level of fitness, with males having significantly higher fitness levels. This could be explained by the fact that males seem to practice sport in a bigger extent than females, since girls should perceive more barriers related to body image, to tiredness and laziness than males [37]. Also, differences in weight were found out, with obese people being less likely to have a good fitness level compared to normal and 
underweight people. This is in line with different findings in the literature confirming that obesity is inversely related to fitness $[17,23,38-41]$.

In the present study, socio-economic status (SES)—such as family's education and occupation - was not significantly associated with fitness levels, as found by some studies [42] and in contrast with some others [43,44], whose difference seems to depend on the accessibility of the sports environment [45]. The present study involves a sample of Southern Italy, an area that for its climatic conditions offers free open places for practicing sports and physical activity, which are accessible also to people with lower economic availability.

In the lifestyle dimension, physical activity and sedentariness were mainly involved as associated factors. Adolescents practicing sport less than three hours/week have a risk six times higher of low fitness level, as previously found by another study [46]. Sports with strength/speed as dominant biomotor ability were found out to be important risk factors of low fitness levels compared to endurance sports.

Those spending more than $3 \mathrm{~h} /$ day in front of PC/internet have more than four times higher risk of low fitness. This result is confirmed in one study, showing that sedentary time influences fitness in children, even though this effect was mediated by physical activity [47]. It suggests that students should be encouraged to decrease time spent in front of PC or the internet, which are often used for leisure rather than for homework.

The multivariate analysis shows that low physical activity is not an independent risk factor of low fitness level, while the univariate shows more than double risk for those practicing low physical activity. This is in line with some studies showing a weak or not significant association between physical activity and physical fitness, also because daily physical activity explains a small proportion of aerobic activity that could be the mere fitness determinant [48-50]. Other studies, contrarily, show that the frequency of engagement in physical activity was highly associated to physical fitness [51,52]. Some studies, moreover, show that physical activity should be always considered together with correct nutrition, since interventions where both determinants were considered significantly increased fitness levels in students [53-55].

In the univariate logistic regression, the "individual" sport type was found to be associated with low fitness levels, but this was not confirmed in the multivariate one, showing that the type of sport is not an independent low fitness risk factor, maybe due to the fact that (a) at this age adolescents choose to practice more than one sport or they decide to change sport activity often (as declared); (b) we discovered a low rate of professional athletes amongst participants.

Among the lifestyle variables, the analysis found out that adolescents consuming alcoholic beverages have a medium/good fitness level. Currently, there is not a consensus on the relationship between fitness/physical activity and alcohol consumption in adolescents [56-58]. One study showed that adolescents with low upper-body musculoskeletal capacity had a lower risk of alcohol consumption [20]. Another one reported a greater likelihood of alcohol consumption and getting drunk occasionally among subjects with a lower aerobic capacity or with a upper and lower muscular strength [21,59]. Thus, authors feel that this alcohol-related behavior should be further analyzed before suggesting strategies and interventions. When, for example, class 4 is considered where almost all subjects are at health risk, a strong association was found out with fitness level; health risk was assessed through two components, one of this being the alcoholic risk; it could be suggested that only drinking more than $12 \mathrm{~g}$ of ethanol per day could be a risk factor for low overall fitness level, while simply drinking alcoholic beverages sometimes is not.

It should also be considered that most of those consuming alcohol are males in the present study, and a significant difference has been found out with around males consuming alcohol twice as much as females; thus, it could be argued that the effect of gender on the fitness level is significantly higher than the effect of alcohol consumption itself.

Food habits do not influence significantly fitness in the present study. This is not in line with the awareness that nutrition is an important part of athletic performance especially during childhood and 
adolescence, in addition to allowing for optimal growth and development [60]. Therefore, this matter has to be further investigated, also considering that some authors have evidenced that the level of adherence to the Mediterranean Diet was also a significant predictor of PF level [41]. An additional study is needed to deeply investigate on the relationship with food habits and consumptions.

This study has a limitation due to the sample not being representative of the national population, since it is limited to adolescents from a metropolitan area in Southern Italy; results cannot be extrapolated to the entire Italian population but can be useful to suggest interventions at local level. Moreover, the tools used for physical activity and sedentariness assessment were based on the validated web-based questionnaire but not on an accelerometer, which is a more objective tool to assess those behaviors.

\section{Conclusions}

This study provides information on the risk factors of the physical fitness in a sample of adolescents from Southern Italy, highlighting that the main predictors of low physical fitness in our sample of adolescents are included in the biological/genetic and lifestyle dimensions. It confirms that females and obese individuals need higher attention not only in terms of number of hours spent in practicing physical activity, but the typology of the performed activity (more strength, more agility, more skills and less generic and vague movements) is also crucial. This work suggests that local actions should be implemented with the aim of increasing sport practices and also reducing sedentary time spent in front of PC/internet.

Author Contributions: A.B. and G.T. conceptualized the research and were involved also on data curation and formal analysis. S.B., G.M. and A.P.a contributed on methodology definition and providing resources. A.G. and G.M. have been involved on manuscript writing and editing. M.G.L., A.P., .A.B. and G.T contributed on project implementation, manuscript revision and project supervision.

Conflicts of Interest: The authors declare no conflict of interest.

\section{References}

1. Guedes, D.P.; Miranda Neto, J.; Lopes, V.P.; Silva, A.J. Health-related physical fitness is associated with selected sociodemographic and behavioral factors in Brazilian school children. J. Phys. Act. Health 2012, 9, 473-480. [CrossRef] [PubMed]

2. Blair, S.N.; Cheng, Y.; Holder, J.S. Is physical activity or physical fitness more important in defining health benefits? Med. Sci. Sports Exerc. 2001, 33 (Suppl. 6), S379-S399. [CrossRef] [PubMed]

3. Williams, P.T. Physical fitness and activity as separate heart disease risk factors: A meta-analysis. Med. Sci. Sports Exerc. 2001, 33, 754-761. [CrossRef] [PubMed]

4. Myers, J.; Kaykha, A.; George, S.; Abella, J.; Zaheer, N.; Lear, S.; Yamazaki, T.; Froelicher, V. Fitness versus physical activity patterns in predicting mortality in men. Am. J. Med. 2004, 117, 912-918. [CrossRef] [PubMed]

5. Warburton, D.E.; Nicol, C.W.; Bredin, S.S. Health benefits of physical activity: The evidence. Can. Med. Assoc. J. 2006, 174, 801-809. [CrossRef] [PubMed]

6. Hogstrom, G.; Nordstrom, A.; Nordstrom, P. Aerobic fitness in late adolescence and the risk of early death: A prospective cohort study of 1.3 million Swedish men. Int. J. Epidemiol. 2016, 45, 1159-1168. [CrossRef] [PubMed]

7. Morrow, J.R., J.; Tucker, J.S.; Jackson, A.W.; Martin, S.B.; Greenleaf, C.A.; Petrie, T.A. Meeting physical activity guidelines and health-related fitness in youth. Am. J. Prev. Med. 2013, 44, 439-444. [CrossRef] [PubMed]

8. Arngrimsson, S.A.; Olafsdottir, A.S. The relation between physical activity, fitness, and fatness in adolescents: A mediation analysis. Am. J. Hum. Biol. Off. J. Hum. Biol. Counc. 2016, 28, 584-586. [CrossRef] [PubMed]

9. Ruiz, J.R.; Castro-Pinero, J.; Artero, E.G.; Ortega, F.B.; Sjostrom, M.; Suni, J.; Castillo, M.J. Predictive validity of health-related fitness in youth: A systematic review. Br. J. Sports Med. 2009, 43, 909-923. [CrossRef] [PubMed] 
10. Kohl, H.W., III; Cook, H.D. (Eds.) Educating the Student Body: Taking Physical Activity and Physical Education to School; National Academies Press: Washington, DC, USA, 2013.

11. Grissom, J.B. Physical fitness and academic achievement. J. Exerc. Physiol. Online 2005, 8, 11-25.

12. Welk, G.J.; Jackson, A.W.; Morrow, J.R., Jr.; Haskell, W.H.; Meredith, M.D.; Cooper, K.H. The association of health-related fitness with indicators of academic performance in Texas schools. Res. Q. Exerc. Sport 2010, 81 (Suppl. 3), S16-S23. [CrossRef] [PubMed]

13. Education, I.P. The Association between School-Based Physical Activity, Including Physical Education, and Academic Performance; US Department of Health and Human Services: Atlanta, GA, USA, 2010.

14. Ortega, F.B.; Ruiz, J.R.; Castillo, M.J.; Sjostrom, M. Physical fitness in childhood and adolescence: A powerful marker of health. Int. J. Obes. 2008, 32, 1-11. [CrossRef] [PubMed]

15. Hainer, V.; Toplak, H.; Stich, V. Fat or fit: What is more important? Diabetes Care 2009, 32 (Suppl. 2), S392-S397. [CrossRef] [PubMed]

16. De Andrade Goncalves, E.C.; Augusto Santos Silva, D.; Gimenes Nunes, H.E. Prevalence and Factors Associated With Low Aerobic Performance Levels in Adolescents: A Systematic Review. Curr. Pediatr. Rev. 2015, 11, 56-70. [CrossRef] [PubMed]

17. Goncalves, E.C.; Silva, D.A. Factors associated with low levels of aerobic fitness among adolescents. Rev. Paulis. Pediatr. 2016, 34, 141-147. [CrossRef]

18. Bianco, A.; Jemni, M.; Thomas, E.; Patti, A.; Paoli, A.; Ramos Roque, J.; Palma, A.; Mammina, C.; Tabacchi, G. A systematic review to determine reliability and usefulness of the field-based test batteries for the assessment of physical fitness in adolescents-The ASSO Project. Int. J. Occup. Med. Environ. Health 2015, 28, 445-478. [CrossRef] [PubMed]

19. Condello, G.; Ling, F.C.; Bianco, A.; Chastin, S.; Cardon, G.; Ciarapica, D.; Conte, D.; Cortis, C.; De Craemer, M.; Di Blasio, A.; et al. Using concept mapping in the development of the EU-PAD framework (EUropean-Physical Activity Determinants across the life course): A DEDIPAC-study. BMC Public Health 2016, 16, 1145. [CrossRef] [PubMed]

20. Grao-Cruces, A.; Fernandez-Martinez, A.; Nuviala, A. Association of fitness with life satisfaction, health risk behaviors, and adherence to the Mediterranean diet in Spanish adolescents. J. Strength Cond. Res. 2014, 28, 2164-2172. [CrossRef] [PubMed]

21. Castro-Pinero, J.; Padilla-Moledo, C.; Ortega, F.B.; Moliner-Urdiales, D.; Keating, X.; Ruiz, J.R. Cardiorespiratory fitness and fatness are associated with health complaints and health risk behaviors in youth. J. Phys. Act. Health 2012, 9, 642-649. [CrossRef] [PubMed]

22. Tabacchi, G.; Bianco, A.; Alessi, N.; Filippi, A.R.; Napoli, G.; Jemni, M.; Censi, L.; Breda, J.; Schumann, N.L.; Firenze, A.; et al. Design, Implementation, and Evaluation of the Adolescents and Surveillance System for the Obesity Prevention Project. Medicine (Baltimore) 2016, 95, e3143. [CrossRef] [PubMed]

23. Jemni, M.; Zaman, M.J.; La Rocca, D.; Tabacchi, G. Southern Italian teenagers: The older they get, the unfit they become with girls worse than boys: A cohort epidemiological study: The adolescents surveillance system for the obesity prevention project (ASSO). Medicine (Baltimore) 2017, 96, e8810. [CrossRef] [PubMed]

24. Bianco, A.; Mammina, C.; Jemni, M.; Filippi, A.R.; Patti, A.; Thomas, E.; Paoli, A.; Palma, A.; Tabacchi, G. A Fitness Index model for Italian adolescents living in Southern Italy: The ASSO project. J. Sports Med. Phys. Fit. 2016, 56, 1279-1288.

25. Tabacchi, G.; Filippi, A.R.; Breda, J.; Censi, L.; Amodio, E.; Napoli, G.; Bianco, A.; Jemni, M.; Firenze, A.; Mammina, C. Comparative validity of the ASSO-Food Frequency Questionnaire for the web-based assessment of food and nutrients intake in adolescents. Food Nutr. Res. 2015, 59, 26216. [CrossRef] [PubMed]

26. Filippi, A.R.; Amodio, E.; Napoli, G.; Breda, J.; Bianco, A.; Jemni, M.; Censi, L.; Mammina, C.; Tabacchi, G. The web-based ASSO-food frequency questionnaire for adolescents: Relative and absolute reproducibility assessment. Nutr. J. 2014, 13, 119. [CrossRef] [PubMed]

27. Cole, T.J.; Bellizzi, M.C.; Flegal, K.M.; Dietz, W.H. Establishing a standard definition for child overweight and obesity worldwide: International survey. BMJ 2000, 320, 1240-1243. [CrossRef] [PubMed]

28. Cole, T.J.; Flegal, K.M.; Nicholls, D.; Jackson, A.A. Body mass index cut offs to define thinness in children and adolescents: International survey. BMJ 2007, 335, 194. [CrossRef] [PubMed]

29. Chastin, S.F.; De Craemer, M.; Lien, N.; Bernaards, C.; Buck, C.; Oppert, J.M.; Nazare, J.A.; Lakerveld, J.; O'Donoghue, G.; Holdsworth, M.; et al. The SOS-framework (Systems of Sedentary behaviors): An 
international transdisciplinary consensus framework for the study of determinants, research priorities and policy on sedentary behavior across the life course: A DEDIPAC-study. Int. J. Behav. Nutr. Phys. Act. 2016, 13, 83. [CrossRef] [PubMed]

30. Stierlin, A.S.; De Lepeleere, S.; Cardon, G.; Dargent-Molina, P.; Hoffmann, B.; Murphy, M.H.; Kennedy, A.; O'Donoghue, G.; Chastin, S.F.; De Craemer, M.; DEDIPAC consortium. A systematic review of determinants of sedentary behavior in youth: A DEDIPAC-study. Int. J. Behav. Nutr. Phys. Act. 2015, 12, 133. [CrossRef] [PubMed]

31. Cole, T.J. Extreme percentiles of the 2000 Centers for Disease Control and Prevention BMI chart and the LMS method. Am. J. Clin. Nutr. 2010, 91, 814. [CrossRef] [PubMed]

32. Mokha, J.S.; Srinivasan, S.R.; Dasmahapatra, P.; Fernandez, C.; Chen, W.; Xu, J.; Berenson, G.S. Utility of waist-to-height ratio in assessing the status of central obesity and related cardiometabolic risk profile among normal weight and overweight/obese children: The Bogalusa Heart Study. BMC Pediatr. 2010, 10, 73. [CrossRef] [PubMed]

33. Maffeis, C.; Banzato, C.; Talamini, G.; Obesity Study Group of the Italian Society of Pediatric Endocrinology and Diabetology. Waist-to-height ratio, a useful index to identify high metabolic risk in overweight children. J. Pediatr. 2008, 152, 207-213. [CrossRef] [PubMed]

34. Currie, C.; Samdal, O.; Boyce, W.; Smith, R. Health Behavior in School-Aged Children: A WHO Cross-National Study (HBSC): Research Protocol for the 2001/2002 Survey; Child and Adolescent Health Research Unit (CAHRU): University of Edinburgh, DK-2100 Copenhagen, Denmark, 2001.

35. Boyce, W.; Torsheim, T.; Currie, C.; Zambon, A. The family affluence scale as a measure of national wealth: Validation of an adolescent self-report measure. Soc. Indic. Res. 2006, 78, 473-487. [CrossRef]

36. World Health Organization. Global Recommendations on Physical Activity for Health; World Health Organization: Geneva, Switzerland, 2010.

37. Fernandez, I.; Canet, O.; Gine-Garriga, M. Assessment of physical activity levels, fitness and perceived barriers to physical activity practice in adolescents: Cross-sectional study. Eur. J. Pediatr. 2017, 176, 57-65. [CrossRef] [PubMed]

38. Gutin, B.; Yin, Z.; Humphries, M.C.; Barbeau, P. Relations of moderate and vigorous physical activity to fitness and fatness in adolescents. Am. J. Clin. Nutr. 2005, 81, 746-750. [CrossRef] [PubMed]

39. Serrano-Sanchez, J.A.; Delgado-Guerra, S.; Olmedillas, H.; Guadalupe-Grau, A.; Arteaga-Ortiz, R.; Sanchis-Moysi, J.; Dorado, C.; Calbet, J.A. Adiposity and age explain most of the association between physical activity and fitness in physically active men. PLoS ONE 2010, 5, e13435. [CrossRef] [PubMed]

40. Tambalis, K.D.; Panagiotakos, D.B.; Psarra, G.; Sidossis, L.S. Inverse but independent trends in obesity and fitness levels among Greek children: A time-series analysis from 1997 to 2007. Obes. Facts 2011, 4, 165-174. [CrossRef] [PubMed]

41. Arnaoutis, G.; Georgoulis, M.; Psarra, G.; Milkonidou, A.; Panagiotakos, D.B.; Kyriakou, D.; Bellou, E.; Tambalis, K.D.; Sidossis, L.S. Association of Anthropometric and Lifestyle Parameters with Fitness Levels in Greek Schoolchildren: Results from the EYZHN Program. Front. Nutr. 2018, 5, 10. [CrossRef] [PubMed]

42. Aktop, A. Socioeconomic status, physical fitness, self-concept, attitude toward physical education, and academic achievement of children. Percept. Mot. Skills 2010, 110, 531-546. [CrossRef] [PubMed]

43. Jiménez Pavón, D.; Ortega, F.B.; Ruiz, J.R.; España Romero, V.; Garcia Artero, E.; Moliner Urdiales, D.; Gómez Martínez, S.; Vicente Rodríguez, G.; Manios, Y.; Beghin, L. Socioeconomic status influences physical fitness in European adolescents independently of body fat and physical activity: The HELENA study. Nutr. Hosp. 2010, 25, 311-316. [PubMed]

44. Bohr, A.D.; Brown, D.D.; Laurson, K.R.; Smith, P.J.; Bass, R.W. Relationship between socioeconomic status and physical fitness in junior high school students. J. School Health 2013, 83, 542-547. [CrossRef] [PubMed]

45. Estabrooks, P.A.; Lee, R.E.; Gyurcsik, N.C. Resources for physical activity participation: Does availability and accessibility differ by neighborhood socioeconomic status? Ann. Behav. Med. 2003, 25, 100-104. [CrossRef] [PubMed]

46. Malina, R.M. Physical activity and fitness: Pathways from childhood to adulthood. Am. J. Hum. Biol. Off. J. Hum. Biol. Counc. 2001, 13, 162-172. [CrossRef]

47. Sandercock, G.R.; Ogunleye, A.A. Screen time and passive school travel as independent predictors of cardiorespiratory fitness in youth. Prev. Med. 2012, 54, 319-322. [CrossRef] [PubMed] 
48. Morrow, J.R., Jr.; Ede, A. Research Quarterly for Exercise and Sport lecture. Statewide physical fitness testing: A big waist or a big waste? Res. Q. Exerc. Sport 2009, 80, 696-701. [CrossRef] [PubMed]

49. Dencker, M.; Thorsson, O.; Karlsson, M.K.; Linden, C.; Svensson, J.; Wollmer, P.; Andersen, L.B. Daily physical activity and its relation to aerobic fitness in children aged 8-11 years. Eur. J. Appl. Phys. 2006, 96, 587-592. [CrossRef] [PubMed]

50. Martinez Vizcaino, V.; Salcedo Aguilar, F.; Franquelo Gutierrez, R.; Solera Martinez, M.; Sanchez Lopez, M.; Serrano Martinez, S.; Lopez Garcia, E.; Rodriguez Artalejo, F. Assessment of an after-school physical activity program to prevent obesity among 9- to 10-year-old children: A cluster randomized trial. Int. J. Obes. 2008, 32, 12-22. [CrossRef] [PubMed]

51. Hogstrom, G.; Nordstrom, A.; Nordstrom, P. High aerobic fitness in late adolescence is associated with a reduced risk of myocardial infarction later in life: A nationwide cohort study in men. Eur. Heart J. 2014, 35, 3133-3140. [CrossRef] [PubMed]

52. Kaminsky, L.A.; Arena, R.; Beckie, T.M.; Brubaker, P.H.; Church, T.S.; Forman, D.E.; Franklin, B.A.; Gulati, M.; Lavie, C.J.; Myers, J.; et al. The importance of cardiorespiratory fitness in the United States: The need for a national registry: A policy statement from the American Heart Association. Circulation 2013, 127, 652-662. [CrossRef] [PubMed]

53. Eather, N.; Morgan, P.J.; Lubans, D.R. Improving the fitness and physical activity levels of primary school children: Results of the Fit-4-Fun group randomized controlled trial. Prev. Med. 2013, 56, 12-19. [CrossRef] [PubMed]

54. Kriemler, S.; Zahner, L.; Schindler, C.; Meyer, U.; Hartmann, T.; Hebestreit, H.; Brunner-La Rocca, H.P.; Van Mechelen, W.; Puder, J.J. Effect of school based physical activity programme (KISS) on fitness and adiposity in primary schoolchildren: Cluster randomised controlled trial. BMJ 2010, 340, c785. [CrossRef] [PubMed]

55. Langford, R.; Bonell, C.; Jones, H.; Pouliou, T.; Murphy, S.; Waters, E.; Komro, K.; Gibbs, L.; Magnus, D.; Campbell, R. The World Health Organization's Health Promoting Schools framework: A Cochrane systematic review and meta-analysis. BMC Public Health 2015, 15, 130. [CrossRef] [PubMed]

56. Delisle, T.T.; Werch, C.E.; Wong, A.H.; Bian, H.; Weiler, R. Relationship between frequency and intensity of physical activity and health behaviors of adolescents. J. School Health 2010, 80, 134-140. [CrossRef] [PubMed]

57. Taliaferro, L.A.; Rienzo, B.A.; Donovan, K.A. Relationships between youth sport participation and selected health risk behaviors from 1999 to 2007. J. School Health 2010, 80, 399-410. [CrossRef] [PubMed]

58. Paupério, T.; Corte-Real, N.; Dias, C.; Fonseca, A. Sport, substance use and satisfaction with life: What relationship? Eur. J. Sport Sci. 2012, 12, 73-80. [CrossRef]

59. Padilla-Moledo, C.; Ruiz, J.R.; Ortega, F.B.; Mora, J.; Castro-Piñero, J. Associations of muscular fitness with psychological positive health, health complaints, and health risk behaviors in Spanish children and adolescents. J. Strength Cond. Res. 2012, 26, 167-173. [CrossRef] [PubMed]

60. Purcell, L.K.; Canadian Paediatric Society, P.S.; Exercise Medicine, S. Sport nutrition for young athletes. Paediatr Child Health 2013, 18, 200-205. [CrossRef] [PubMed]

(C) 2018 by the authors. Licensee MDPI, Basel, Switzerland. This article is an open access article distributed under the terms and conditions of the Creative Commons Attribution (CC BY) license (http://creativecommons.org/licenses/by/4.0/). 